\title{
Effect of cyproterone acetate on alpha1-adrenoceptor subtypes in rat vas deferens
}

\section{Campos, \\ P.L. Morais and A.S. Pupo}

Departamento de Farmacologia, Instituto de Biociências, Universidade Estadual Paulista, Botucatu, SP, Brasil

\section{Correspondence \\ A.S. Pupo \\ Departamento de Farmacologia Instituto de Biociências, UNESP \\ 18618-000 Botucatu, SP \\ Brasil \\ Fax: +55-14-3815-3744 \\ E-mail: aspupo@ibb.unesp.br}

Research supported by FAPESP (No. 98/11031-2 to A.S. Pupo). M. Campos and P.L. Morais were recipients of studentships from FAPESP and CAPES, respectively.

Received February 25, 2003

Accepted August 12, 2003
Abstract

Gonadal hormones regulate the expression of $\alpha_{1}$-adrenoceptor subtypes in several tissues. The present study was carried out to determine whether or not cyproterone acetate, an anti-androgenic agent, regulates the $\alpha_{1}$-adrenoceptor subtypes that mediate contractions of the rat vas deferens in response to noradrenaline. The actions of subtype selective $\alpha_{1}$-antagonists were investigated in vas deferens from control and cyproterone acetate-treated rats $(10 \mathrm{mg} / \mathrm{day}, s c$, for 7 days). Prazosin $\left(\mathrm{pA}_{2} \approx 9.5\right)$, phentolamine $\left(\mathrm{pA}_{2} \approx 8.3\right)$ and yohimbine $\left(\mathrm{pA}_{2}\right.$ $\approx 6.7$ ) presented competitive antagonism consistent with activation of $\alpha_{1}$-adrenoceptors in vas deferens from both control and treated rats. The $\mathrm{pA}_{2}$ values estimated for WB $4101(\approx 9.5)$, benoxathian $(\approx 9.7)$, 5-methylurapidil $(\approx 8.5)$, indoramin $(\approx 8.7)$ and BMY $7378(\approx 6.8)$ indicate that $\alpha_{1 \mathrm{~A}}$-adrenoceptors are involved in the contractions of the vas deferens from control and cyproterone acetate-treated rats. Treatment of the vas deferens from control rats with the $\alpha_{1 \mathrm{~B}} / \alpha_{1 \mathrm{D}}$-adrenoceptor alkylating agent chloroethylclonidine had no effect on noradrenaline contractions, supporting the involvement of the $\alpha_{1 \mathrm{~A}}$-subtype. However, this agent partially inhibited the contractions of vas deferens from cyproterone acetate-treated rats, suggesting involvement of multiple receptor subtypes. To further investigate this, the actions of WB 4101 and chloroethylclonidine were reevaluated in the vas deferens from rats treated with cyproterone acetate for 14 days. In these organs WB 4101 presented complex antagonism characterized by a Schild plot with a slope different from unity $(0.65 \pm 0.05)$. After treatment with chloroethylclonidine, the complex antagonism presented by WB 4101 was converted into classical competitive antagonism, consistent with participation of $\alpha_{1 \mathrm{~A}}$-adrenoceptors as well as $\alpha_{1 \mathrm{~B}}$-adrenoceptors. These results suggest that cyproterone acetate induces plasticity in the $\alpha_{1}$-adrenoceptor subtypes involved in the contractions of the vas deferens.

\section{Introduction}

Three different $\alpha_{1}$-adrenoceptor subtypes, $\alpha_{1 \mathrm{~A}^{-}}, \alpha_{1 \mathrm{~B}^{-}}$and $\alpha_{1 \mathrm{D}^{-}}$-adrenoceptors, have been cloned (1). Several drugs interact selectively with one or more of these subtypes in func-
Key words

- Alpha1-adrenoceptors

- Vas deferens

- Cyproterone acetate tional and/or radioligand binding studies (2). Additional $\alpha_{1}$-adrenoceptor heterogeneity has been suggested by functional studies in which prazosin showed low potency in inhibiting 
contractions of certain vascular tissues in response to adrenergic agonists (2). However, prazosin also shows low potency for inhibition of $\left[{ }^{3} \mathrm{H}\right]$-inositol phosphate formation in cell lines expressing each of the human $\alpha_{1 \mathrm{~A}}$-adrenoceptor splice variants, suggesting that these additional subtypes may represent low affinity state(s) of the $\alpha_{1 A^{-}}$ adrenoceptors and not a different protein encoded by a different gene $(3,4)$.

Although some information is available concerning the mechanisms that regulate acute expression of $\alpha_{1}$-adrenoceptors such as desensitization and internalization (5), much less is known about the factors that regulate the expression of $\alpha_{1}$-adrenoceptor subtypes for longer periods of time. However, some studies have shown that gonadal hormones differentially regulate the expression of $\alpha_{1}$-adrenoceptor subtypes in several tissues (6-12). For instance, previous data from our laboratory have shown that castration changes the $\alpha_{1}$-adrenoceptor subtypes involved in the contractions of the rat vas deferens in response to noradrenaline (8) and that testosterone replacement treatment of castrated rats prevents this plasticity (12).

The present study was carried out to determine whether or not cyproterone acetate, an anti-androgenic drug, induces such plasticity in the $\alpha_{1}$-adrenoceptor subtypes involved in the contractions of the rat vas deferens in response to noradrenaline. To this end, we determined the actions of $\alpha_{1-}$ selective antagonists against the contractions induced by noradrenaline in vas deferens from cyproterone acetate-treated and control untreated rats.

\section{Material and Methods}

\section{Cyproterone acetate treatment and vas deferens isolation}

Male Wistar rats weighing 280-360 g (16-20 weeks old) were treated with $10 \mathrm{mg} /$ day cyproterone acetate $(s c)$ for 7 or 14 days and were killed at the end of the treatment. The vasa deferentia from cyproterone acetate-treated and age-matched control rats (untreated) were excised, separated from surrounding tissue, weighed, and immediately mounted for contractility studies. To check the anti-androgenic action of the treatment, the wet weights of the ventral prostate and seminal vesicle were also determined. Previous experiments using larger doses of cyproterone acetate (up to $35 \mathrm{mg} /$ day for 7 days) did not induce additional significant wet weight reductions, suggesting that $10 \mathrm{mg} /$ day was the maximal effective dose (measurements on 5 rats, $\mathrm{P}>0.05$ ). The experimental procedures were approved by the Ethics Committee for Animal Research from UNESP, Botucatu, SP, Brazil.

\section{Functional studies}

For the study of contractility the vasa deferentia were mounted under $9.80 \mathrm{mN}$ of tension in $10 \mathrm{ml}$ organ baths containing a nutrient solution of the following composition: $138 \mathrm{mM} \mathrm{NaCl}, 5.7 \mathrm{mM} \mathrm{KCl}, 1.8 \mathrm{mM}$ $\mathrm{CaCl}_{2}, 0.36 \mathrm{mM} \mathrm{NaH}_{2} \mathrm{PO}_{4}, 15 \mathrm{mM} \mathrm{NaHCO}_{3}$, and $5.5 \mathrm{mM}$ dextrose, prepared in glassdistilled, deionized water and maintained at $30^{\circ} \mathrm{C}, \mathrm{pH} 7.4$ (8). Vasa deferentia from control or cyproterone acetate-treated rats were equilibrated for $30 \mathrm{~min}$ before the beginning of the experiments. After this period, two or three cumulative concentration-response curves for noradrenaline were obtained, and then $6 \mu \mathrm{M}$ cocaine, $10 \mu \mathrm{M}$ corticosterone and $0.1 \mu \mathrm{M}$ propranolol were added to the organ bath in order to block neuronal and extraneuronal uptake and $\mathrm{B}$-adrenoceptor, respectively. The interval between concentration-response curves was $45 \mathrm{~min}$. Competitive antagonists were added to the bath 45 min before and during the contractile responses to noradrenaline. After incubation with $100 \mu \mathrm{M}$ chloroethylclonidine for 45 min the preparation was washed repeatedly (at least ten times) for $30 \mathrm{~min}$ before the 
concentration-response curve to noradrenaline.

\section{Calculation of $\mathrm{pA}_{2}$ values}

The $\mathrm{pA}_{2}$ values for the competitive antagonists were calculated by Schild regression analysis (13). The ratios between the half-maximal concentrations of noradrenaline (concentration-ratios, $r$ ) were calculated only when the maximal amplitude of the concentration-response curve in the presence of the competitive antagonists was similar to that obtained in its absence. Data were plotted as log antagonist concentrations (M) $v s \log (\mathrm{r}-1)$. For calculation purposes the slope parameter was constrained to 1.0 when not statistically different from unity.

\section{Drugs}

Drugs were obtained from the following sources: cyproterone acetate (Androcur ${ }^{\circledR}$; Berlimed, São Paulo, SP, Brazil, or Galena, Campinas, SP, Brazil); cocaine (Cocainum Hydrochloricum puriss.; C.H. Boehringer, Ingelheim, Germany). Corticosterone and noradrenaline $[( \pm)$-arterenol $\mathrm{HCl}]$ were from Sigma (St. Louis, MO, USA). Benoxathian $\mathrm{HCl}$, chloroethylclonidine $2 \mathrm{HCl}$, BMY 7378 (8-[2-[4-(2-methoxyphenyl)-1-piperazinyl] ethyl]-8-azaspiro [4,5] decane-7, 9-dione dihydrochloride), 5-methylurapidil $\mathrm{HCl}$, prazosin $\mathrm{HCl}$, phentolamine $\mathrm{HCl},( \pm)$-propranolol HCl, WB 4101 (2-(2,6-dimethoxyphenoxyethyl) aminomethyl-1, 4-benzodioxane hydrochloride), and yohimbine $\mathrm{HCl}$ were from Research Biochemicals Inc. (RBI/ Sigma), Natick, MA, USA. Indoramin hydrochloride was a gift from Wyeth-Fontoura (São Paulo, SP, Brazil). Drugs were dissolved in distilled water or $1 \mathrm{mM}$ dimethylsulfoxide, kept frozen and discarded after 20 days. Noradrenaline was dissolved in $10 \mathrm{mN}$ $\mathrm{HCl}$ each day shortly before the experiments. Cyproterone acetate was solubilized in soybean oil.

\section{Statistical analysis}

All data are reported as means \pm SEM for $\mathrm{N}$ experiments. Differences between mean values were tested for statistical significance $(\mathrm{P}<0.05)$ using paired or unpaired Student $t$-tests or analysis of variance (ANOVA) followed by the Newman-Keuls test for multiple comparisons.

\section{Results}

Effects of treatment with cyproterone acetate for 7 days on the wet weight of the vas deferens, ventral prostate and seminal vesicle

Since no significant effect of cyproterone acetate on total rat weight was observed, a direct comparison of the wet weight of the vas deferens, ventral prostate and seminal vesicle was used to determine the efficacy of the anti-androgenic treatment. The treatment induced significant reductions of the wet weights of the vas deferens, ventral prostate and seminal vesicle (Table 1). The wet weights of the same organs from surgically castrated rats (orchiectomized 7 days before) are shown in Table 1 for comparison. Surgical castration induced more marked reductions of the weights of the organs $(\mathrm{P}<$ $0.05)$.

Effects of noradrenaline on vas deferens from control rats and from rats treated with cyproterone acetate for 7 days

Nearly rhythmic spontaneous contractions of low magnitude were observed in a few vasa deferentia from rats treated with cyproterone acetate for 7 days, while none of the organs from control rats presented spontaneous contractions.

Noradrenaline induced concentrationdependent contractions of the vas deferens from control rats and from rats treated with cyproterone acetate for 7 days (Figure 1). The maximal contraction induced by nor- 
Figure 1. Concentration-response curves for noradrenaline on vas deferens from control (open circles) and cyproterone acetate-treated rats (filled circles). Data are reported as means \pm SEM of 24-31 experiments on vas deferens from 24 to 31 rats in each group. The rats received cyproterone $(10$ $\mathrm{mg} /$ day, sc) for 7 days. adrenaline in the vas deferens from cyproterone acetate-treated rats $(19.7 \pm 0.5 \mathrm{mN}, \mathrm{N}=$ 24) was significantly lower than in vas deferens from control rats $(23.2 \pm 0.5 \mathrm{mN}, \mathrm{N}=31$; $\mathrm{P}<0.05)$. However, the potency of noradrenaline (assessed by the $\mathrm{pD}_{2}$ values) in the vas deferens from control rats $(7.0 \pm 0.1$, $\mathrm{N}=31$ ) was not different from that in vas deferens from cyproterone acetate-treated rats $(7.0 \pm 0.1, \mathrm{~N}=24)$.

\section{Effects of selective $\alpha$-adrenoceptor antagonists} on noradrenaline contractions

The concentration-response curves for noradrenaline applied to the vas deferens from control rats and from rats treated with cyproterone acetate for 7 days were competitively antagonized by prazosin $\left(\alpha_{1}\right.$-selective), phentolamine (non- $\alpha_{1} / \alpha_{2}$-selective) and yohimbine ( $\alpha_{2}$-selective) as characterized by the slopes in the Schild plots not different from unity and by the lack of effect

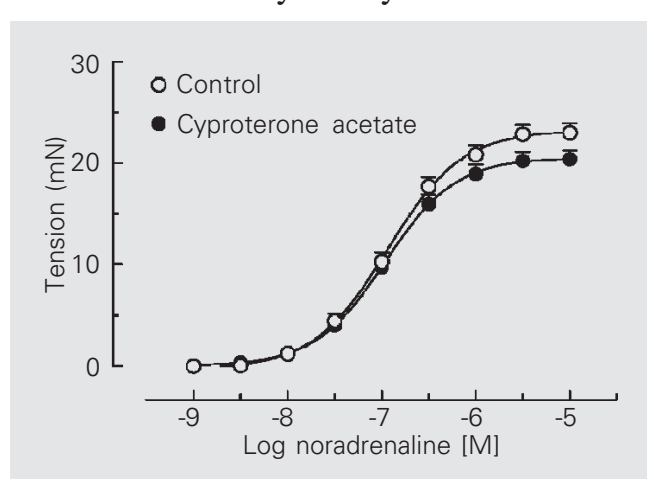

Table 1. Effect of cyproterone acetate treatment on the wet weights (in $\mathrm{mg}$ ) of rat vas deferens, ventral prostate and seminal vesicle.

\begin{tabular}{llll}
\hline Animals & Vas deferens & Ventral prostate & Seminal vesicle \\
\hline Control & $71.4 \pm 2.1$ & $176.8 \pm 11.4$ & $271.4 \pm 10.0$ \\
Cyproterone acetate-treated & $56.0 \pm 1.5^{\mathrm{a}}$ & $119.1 \pm 7.1^{\mathrm{a}}$ & $164.0 \pm 0.3^{\mathrm{a}}$ \\
Surgically castrated & $49 \pm 1.7^{\mathrm{ab}}$ & $47.0 \pm 0.2^{\mathrm{ab}}$ & $107.2 \pm 4.7^{\mathrm{ab}}$ \\
\hline
\end{tabular}

Rats received cyproterone acetate $(10 \mathrm{mg} / \mathrm{day}, \mathrm{sc})$ for 7 days. Data are reported as means \pm SEM for 14 to 41 rats in each group. For comparison, the wet weights of the same organs from 7-day surgically castrated rats are included.

aP $<0.05$ compared to the respective value of control rats. ${ }^{\text {bP }}<0.05$ compared to the respective value for cyproterone acetate-treated rats (ANOVA followed by NewmanKeuls test). of these antagonists on the maximal responses to noradrenaline (Figure 2 and Table 2). The rank order of potency found for these antagonists (prazosin $>$ phentolamine $>$ yohimbine) indicates that the contractions induced by noradrenaline in vas deferens from control and cyproterone acetate-treated rats are mediated by $\alpha_{1}$-adrenoceptors.

Effects of subtype-selective $\alpha_{1}$-adrenoceptor antagonists on noradrenaline contractions

In vas deferens from control rats and from rats treated with cyproterone acetate for 7 days, the antagonists WB 4101 and benoxathian $\left(\alpha_{1 \mathrm{~A}} / \alpha_{1 \mathrm{D}}\right.$-selective $)$, indoramin and 5-methylurapidil ( $\alpha_{1 \mathrm{~A}}$-selective), and BMY $7378\left(\alpha_{1 D}\right.$-selective $)$ inhibited noradrenaline contractions showing competitive antagonisms (Figure 3 and Table 2). The slopes of the Schild plots for these antagonists did not differ from unity.

\section{Effect of chloroethylclonidine on} noradrenaline contractions

The incubation of vas deferens from control rats with the $\alpha_{1 \mathrm{~B}} / \alpha_{1 \mathrm{D}}$-adrenoceptor alkylating agent chloroethylclonidine $(100 \mu \mathrm{M}$, $45 \mathrm{~min}$ ) resulted in no significant change in the concentration-response curves for noradrenaline (Figure 4A, Table 3). However, this same treatment resulted in a 3 -fold rightward shift in the concentration-response curve for noradrenaline in vas deferens from cyproterone acetate-treated rats associated with an $\approx 30 \%$ reduction of the maximal response (Figure 4B, Table 3 ).

Effects of longer cyproterone acetate treatments on tissue wet weight and on the antagonism of noradrenaline by WB 4101 and chloroethylclonidine

The fact that chloroethylclonidine was effective on the vas deferens from rats treated with cyproterone acetate for 7 days sug- 

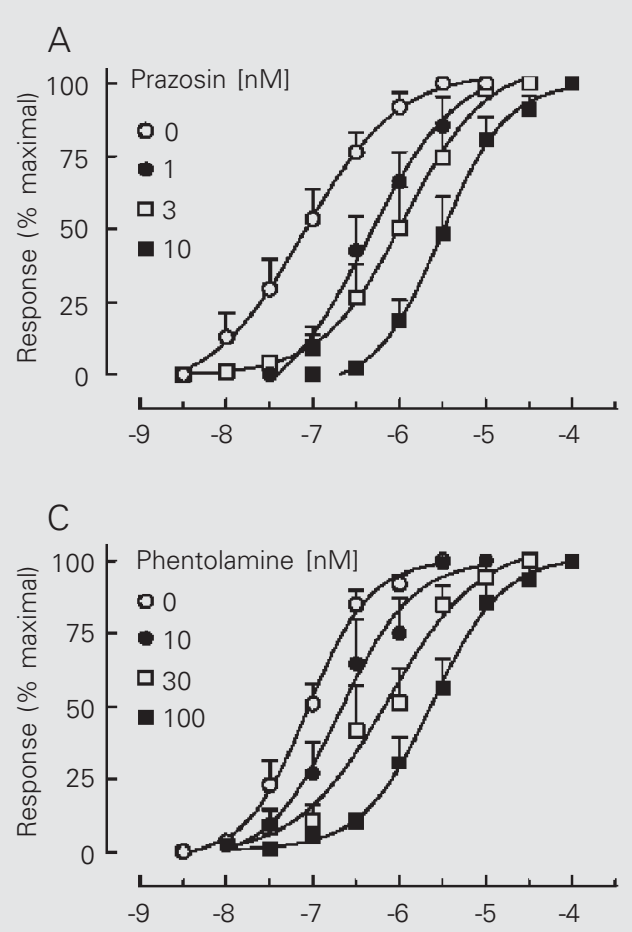

E
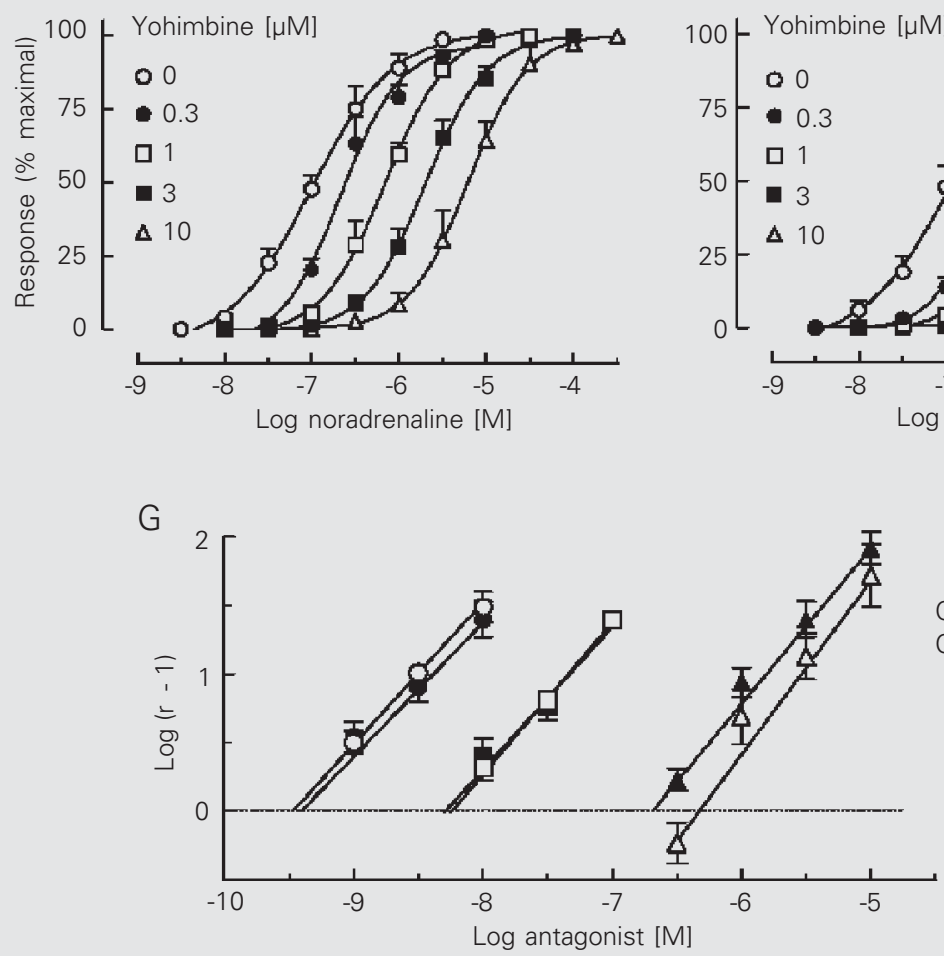

$\mathrm{F}$
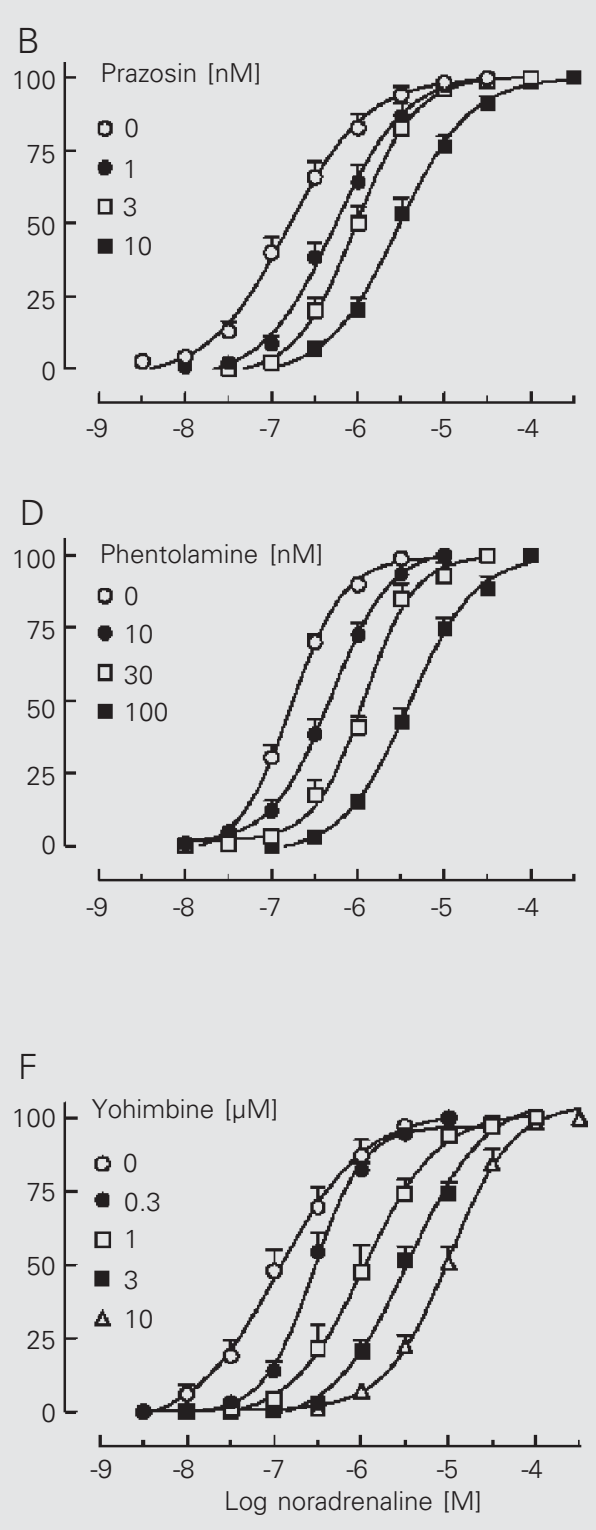

D

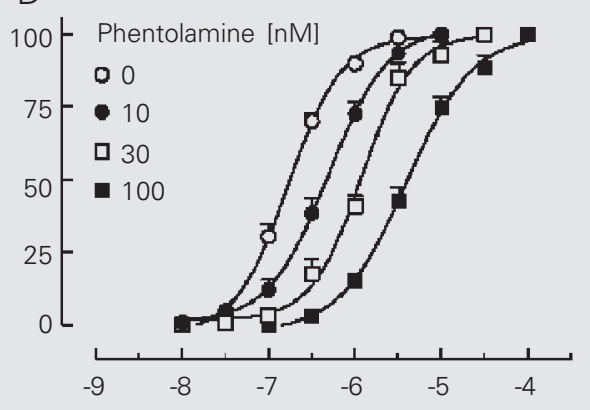

Control (open)

Cyproterone acetate (closed)

- Prazosin

口 Phentolamine

$\Delta$ \& Yohimbine
Figure 2. Concentration-response curves for noradrenaline in the absence and presence of increasing concentrations of prazosin (A and $B$ ), phentolamine $(C$ and $D)$ and yohimbine $(E$ and $F$ ) in vas deferens from control ( $A, C$ and $E$ ) and cyproterone acetate-treated rats $(B, D$ and F). The Schild plots obtained for prazosin, phentolamine and yohimbine are presented in $G$. Each symbol indicates the mean and the vertical line, when larger than the symbol, the SEM of 412 determinations for 4 to 6 rats in each group. When appropriate, the rats received cyproterone acetate (10 mg/day, sc) for 7 days. 
Table 2. Effect of cyproterone acetate treatment on the $\mathrm{pA}_{2}$ and slope values of $\alpha$ adrenoceptor antagonists against noradrenaline-induced contractions of vas deferens.

\begin{tabular}{|c|c|c|c|c|}
\hline \multirow[t]{2}{*}{ Antagonist } & \multicolumn{2}{|c|}{ Control } & \multicolumn{2}{|c|}{ Cyproterone acetate } \\
\hline & $\mathrm{pA}_{2}$ & slope & $\mathrm{pA}_{2}$ & slope \\
\hline Prazosin & $9.51 \pm 0.19$ & $0.99 \pm 0.05$ & $9.42 \pm 0.25$ & $0.97 \pm 0.10$ \\
\hline Phentolamine & $8.25 \pm 0.10$ & $1.14 \pm 0.06$ & $8.35 \pm 0.14$ & $1.06 \pm 0.08$ \\
\hline Yohimbine & $6.67 \pm 0.24$ & $0.99 \pm 0.07$ & $6.77 \pm 0.06$ & $1.11 \pm 0.08$ \\
\hline WB 4101 & $9.61 \pm 0.03$ & $1.01 \pm 0.03$ & $9.45 \pm 0.05$ & $0.93 \pm 0.05$ \\
\hline Benoxathian & $9.83 \pm 0.04$ & $0.87 \pm 0.08$ & $9.57 \pm 0.04$ & $1.00 \pm 0.12$ \\
\hline Indoramin & $8.79 \pm 0.07$ & $0.92 \pm 0.06$ & $8.63 \pm 0.03$ & $1.03 \pm 0.04$ \\
\hline 5-Methylurapidil & $8.58 \pm 0.06$ & $0.89 \pm 0.06$ & $8.56 \pm 0.06$ & $1.01 \pm 0.05$ \\
\hline BMY 7378 & $6.89 \pm 0.05$ & $1.11 \pm 0.07$ & $6.85 \pm 0.05$ & $0.98 \pm 0.07$ \\
\hline
\end{tabular}

Rats received cyproterone acetate $(10 \mathrm{mg} / \mathrm{day}, \mathrm{sc})$ for 7 days. Data are reported as means \pm SEM of 4 to 12 determinations on tissue from 4 to 6 rats in each group.

gested that the anti-androgenic treatment was not of long enough duration to allow detection of alterations in the actions of $\alpha_{1}$ adrenoceptor selective antagonists such as WB 4101. Therefore, the actions of WB 4101 were determined against the contractions induced by noradrenaline in vas deferens from rats treated with cyproterone acetate for 14 days. Treatment of the rats with cyproterone acetate for 14 days induced more marked reductions in the wet weights of the vas deferens $(47 \pm 1.0 \mathrm{mg}, \mathrm{N}=5 ; \mathrm{P}<0.05)$, ventral prostate $(98 \pm 3.0 \mathrm{mg}, \mathrm{N}=5 ; \mathrm{P}<0.05)$ and seminal vesicle $(115 \pm 4.0 \mathrm{mg}, \mathrm{N}=5$; $\mathrm{P}<0.05$ ) than the treatment for 7 days (Table 1). Noradrenaline induced concentration-dependent contractions in vas deferens from rats treated with cyproterone acetate for 14 days with the same potency $\left(\mathrm{pD}_{2}=7.2 \pm 0.2\right.$, $\mathrm{N}=5$ ) as observed in vas deferens from control rats or from rats treated with cyproterone acetate for 7 days. However, the maximal contraction induced by noradrenaline in vas deferens from rats treated with cyproterone acetate for 14 days $(17.7 \pm 0.5 \mathrm{mN}, \mathrm{N}=$ $5)$ was smaller than that induced in vas deferens from control rats but not different from that induced in vasa from rats treated for 7 days. The antagonist WB 4101 also presented competitive antagonism of the contractions induced by noradrenaline in vas deferens from rats treated with cyproterone acetate for 14 days, as indicated by the slope of the Schild plot not different from the theoretical unity $\left(\mathrm{pA}_{2}=9.31 \pm 0.10\right.$, slope $=$ $0.88 \pm 0.05$; see the solid line in Figure 5B). However, a closer inspection of this antagonism shows that the slope of the line in the Schild plot did not differ from the theoretical unity only if a relatively wide range of antagonist concentrations ( 1 to $100 \mathrm{nM}$ ) was considered. Alternatively, if only the first four concentrations of WB 4101 were used to construct the Schild plot a slope of $0.65 \pm$ 0.05 was obtained, which was smaller than 1.0 ( $\mathrm{P}>0.05$; see the broken line in Figure 5C).

In order to determine whether this complex antagonism presented by WB 4101 and the effectiveness of chloroethylclonidine share common mechanisms, the actions of WB 4101 were reevaluated against the contractions in response to noradrenaline that were resistant to this alkylating agent (Figure $5 \mathrm{~A}$ ). The antagonism presented by WB 4101 after chloroethylclonidine treatment is consistent with classic competitive antagonism regardless of the concentrations of antagonist used to construct the Schild plot $\left(\mathrm{pA}_{2}=9.54 \pm 0.04 ;\right.$ slope $=1.08 \pm 0.03, \mathrm{~N}=$ 5; Figure 5). This suggests that the complex antagonism presented by WB 4101 is related to a component of the response to noradrenaline which is sensitive to chloroethylclonidine.

\section{Discussion}

We investigated the effects of treatment with the anti-androgen cyproterone acetate on $\alpha_{1}$-adrenoceptor subtypes involved in the contractions of the rat vas deferens in response to noradrenaline using subtype-selective competitive antagonists. Treatment of the rats with cyproterone acetate reduced the wet weights of the vas deferens, ventral prostate and seminal vesicle as expected according to the anti-androgenic action of this drug. However, surgical castration induced 


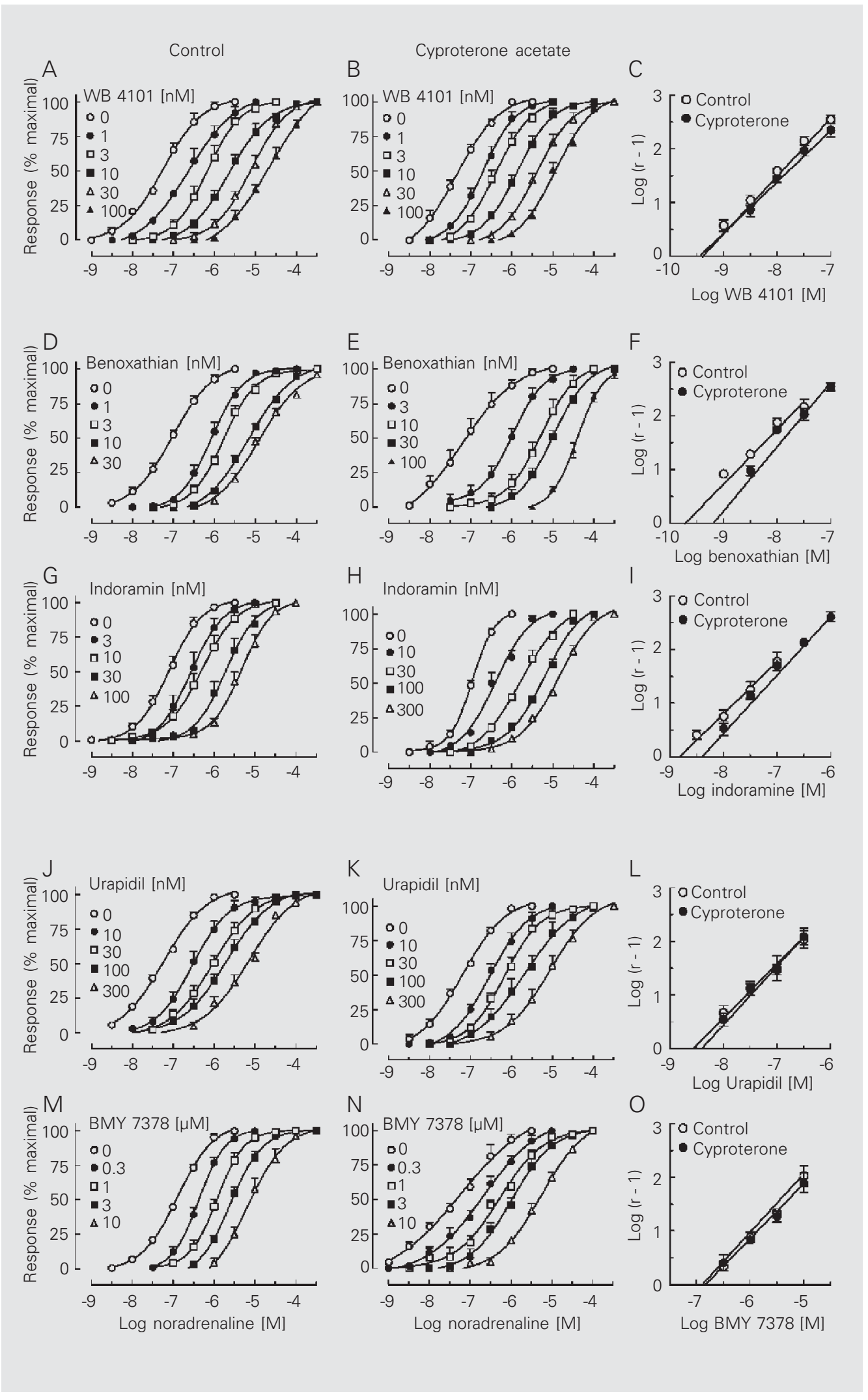

Figure 3. Concentration-response curves for noradrenaline in the absence and presence of increasing concentrations of WB 4101 (A and B), benoxathian $(D$ and $E$ ), indoramin ( $G$ and $H)$, 5-methylurapidil ( $\mathrm{J}$ and $\mathrm{K}$ ), and BMY 7378 ( $M$ and $N$ ), in vas deferens from control (A, D, G, $\mathrm{J}$ and $\mathrm{M})$ and cyproterone acetate-treated rats $(B, E, H, K$ and $N)$. The Schild plots obtained for WB 4101, benoxathian, indoramin, BMY 7378, and 5-methylurapidil are presented in $C, F, I$, $L$, and $O$, respectively. Each symbol indicates the mean and the vertical line, when larger than the symbol, the SEM of 412 determinations for 4 to 6 rats in each group. The rats received cyproterone acetate $(10 \mathrm{mg} /$ day, sc) for 7 days. 
Figure 4. Concentration-response curves for noradrenaline obtained before (open circles) and after (filled circles) treatment with $100 \mu \mathrm{M}$ chloroethylclonidine (CEC) for $45 \mathrm{~min}$ for vas deferens from control (A) and cyproterone acetate-treated rats (B). Each symbol indicates the mean and the vertical line, when larger than the symbol, the SEM of 5-8 measurements on tissue from 4 to 6 rats in each group. When appropriate, rats were treated with cyproterone acetate (10 mg/day, sc) for 7 days.

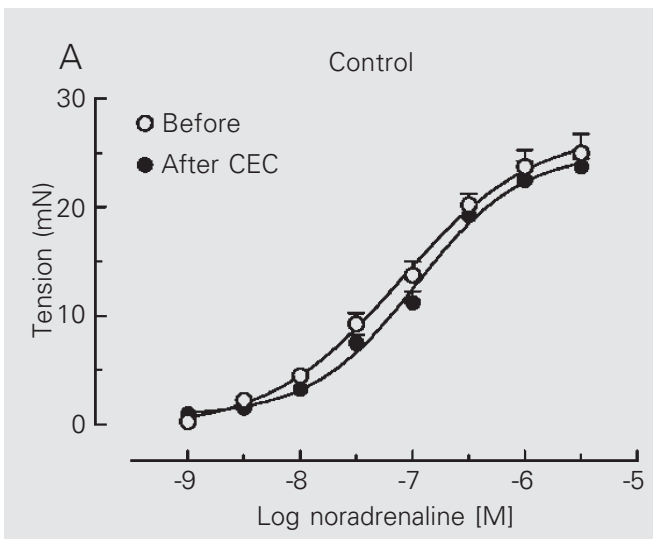

B

Cyproterone acetate

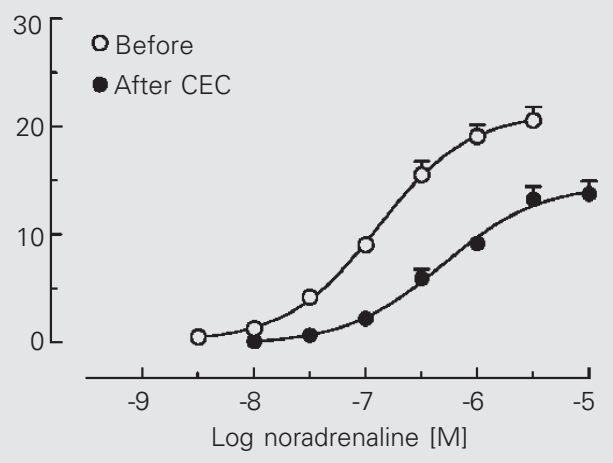

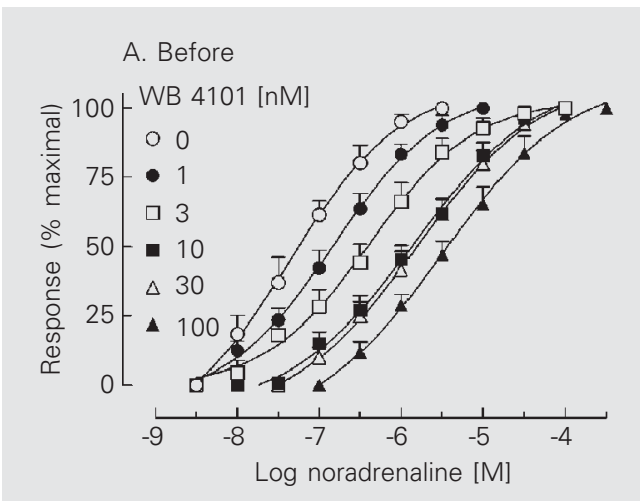
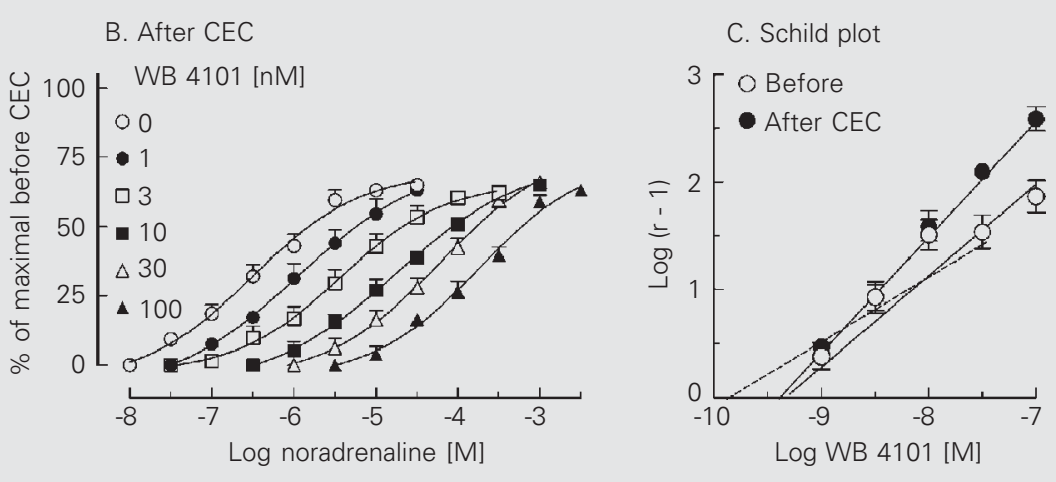

Figure 5. A, Concentration-response curves for noradrenaline (before treatment with $100 \mu \mathrm{M}$ chloroethylclonidine for 45 min) obtained for vas deferens from rats treated with cyproterone acetate $(10 \mathrm{mg} /$ day, SC, for 14 days) in the absence (open circles) and presence of WB 4101 at concentrations of 1.0 (filled circles), 3.0 (open squares), 10 (filled squares), 30 (open triangles) and $100 \mathrm{nM}$ (filled triangles). B, Concentration-response curves for noradrenaline (after treatment with $100 \mu \mathrm{M}$ chloroethylclonidine for $45 \mathrm{~min}$ ) obtained for vas deferens from cyproterone acetate-treated rats $(10 \mathrm{mg} / \mathrm{day}, \mathrm{sc}$, for 14 days) in the absence (open circles) and presence of WB 4101 at concentrations of 1.0 (filled circles), 3.0 (open squares), 10 (filled squares), 30 (open triangles) and $100 \mathrm{nM}$ (filled triangles). C, Schild plot obtained for WB 4101. Each symbol represents the mean and the vertical line, when larger than the symbol, the SEM of 5 determinations on tissue from 5 rats. CEC $=$ chloroethylclonidine.

Table 3. Effects of chloroethylclonidine on $\mathrm{pD}_{2}$ and maximal contractions in response to noradrenaline acting on vas deferens from control and cyproterone acetate-treated rats.

\begin{tabular}{lrrrrr}
\hline & \multicolumn{2}{c}{ Control } & & \multicolumn{2}{c}{ Cyproterone acetate } \\
\cline { 2 - 3 } \cline { 5 - 6 } & \multicolumn{1}{c}{$\mathrm{pD}_{2}$} & $\operatorname{Emax}(\%)$ & & \multicolumn{1}{c}{$\mathrm{pD}_{2}$} & Emax (\%) \\
\hline Before treatment & $7.1 \pm 0.1$ & $100 \pm 10$ & & $7.0 \pm 0.1$ & $100 \pm 9$ \\
After treatment & $7.0 \pm 0.1$ & $95 \pm 9$ & & $6.5 \pm 0.1^{\mathrm{a}}$ & $71 \pm 9^{\mathrm{a}}$ \\
\hline
\end{tabular}

The tissue was treated with $100 \mu \mathrm{M}$ chloroethylclonidine for $45 \mathrm{~min}$ and extensively washed (at least ten times) before the measurement. Data are reported as means \pm SEM of 5 to 8 determinations on tissue from 5 to 8 rats in each group. The rats were treated with cyproterone acetate $(10 \mathrm{mg} / \mathrm{day}, \mathrm{sc})$ for 7 days. Emax is reported as percent of maximal response before chloroethylclonidine treatment.

aP $<0.05$ compared to the respective value before treatment (Student $t$-test). more pronounced reductions in the wet weights of these organs, showing that treatment with cyproterone acetate had only a partial anti-androgenic action in comparison to bilateral orchiectomy.

Cyproterone acetate treatment reduced the maximal contraction induced by noradrenaline in the vas deferens without changing the potency of this agonist, as indicated by the $\mathrm{pD}_{2}$ values. Interestingly, cyproterone acetate treatment resulted in atrophy of the vas deferens as characterized by the loss of approximately $20 \%$ of the wet weight of the organ. Therefore, it is tempting to associate 
the reduction in the maximal contraction in response to noradrenaline with atrophy of the organ. However, other factors may be involved. For example, it is known that treatment of the rats with cyproterone acetate induces a drastic down-regulation of L-type voltage-dependent calcium channels in the vas deferens (14), as does bilateral orchiectomy (15). This may contribute to the reduced responsiveness of the vas deferens to noradrenaline since the contractions induced by this agonist are dependent on calcium influx through L-type voltage-dependent calcium channels $(16,17)$.

The actions of a series of subtype-selective antagonists were determined against the contractions induced by noradrenaline to determine the effects of cyproterone acetate treatment on $\alpha_{1}$-adrenoceptor subtypes. The results obtained with these reversible competitive antagonists indicate that noradrenaline-induced contractions in vas deferens from both control and cyproterone acetatetreated rats are due to the activation of $\alpha_{1 \mathrm{~A}^{-}}$ adrenoceptors as judged by the high $\mathrm{pA}_{2}$ values found for the $\alpha_{1 \mathrm{~A}}$-selective antagonists WB 4101, 5-methylurapidil and indoramin. In addition, the low potency shown by the $\alpha_{1 \mathrm{D}}$-selective antagonist BMY 7378 against the contractions induced by noradrenaline in both organs further indicates that $\alpha_{1 \mathrm{~A}}$-adrenoceptors are involved in this functional response. The conclusion that $\alpha_{1 A^{-}}$ adrenoceptors are involved in the contractions of the vas deferens agrees with previous studies from this and other laboratories (8,16-19). Interestingly, the $\alpha_{1 \mathrm{~A}}$-adrenoceptor is not the only $\alpha_{1}$-subtype expressed in the rat vas deferens since radioligand binding experiments have detected the presence of $\alpha_{1 \mathrm{~A}^{-}}$and $\alpha_{1 \mathrm{~B}^{-}}$-adrenoceptors (20-22) and mRNA species for $\alpha_{1 A^{-}}, \alpha_{1 B^{-}}$and $\alpha_{1 D^{-}}$subtypes have been detected in this organ (2325, and Pupo AS and Avellar MCW, unpublished observations). The roles of the $\alpha_{1 B^{-}}$ and $\alpha_{1 \mathrm{D}}$-adrenoceptor subtypes in the rat vas deferens remain to be established.
The lack of effect of chloroethylclonidine on vas deferens from control rats also supports the involvement of $\alpha_{1 \mathrm{~A}}$-adrenoceptors in these contractions. However, chloroethylclonidine inhibited, at least in part, the contractions induced by noradrenaline in vas deferens from cyproterone acetate-treated rats. Since chloroethylclonidine alkylates $\alpha_{1 B^{-}}$and $\alpha_{1 D^{-a d r e n o c e p t o r s, ~ t h i s ~ r e s u l t ~ s u g-~}}$ gests that multiple subtypes may participate in the contractions of the vas deferens from cyproterone acetate-treated rats. This led us to test the effects of longer treatments with cyproterone acetate. WB 4101 showed complex antagonism against the contractions of the vas deferens from rats treated with cyproterone acetate for 14 days in response to noradrenaline. The complex antagonism of WB 4101 was observed with the effects of the concentrations of 1 to $30 \mathrm{nM}$ which resulted in a slope parameter in the Schild plot much lower than theoretical unity, also indicating that mixed receptor populations may be involved in the contractions induced by noradrenaline. Accordingly, after treatment with chloroethylclonidine of the vas deferens from rats treated with cyproterone acetate for 14 days, the complex antagonism presented by WB 4101 was converted into classical competitive antagonism resulting in a high $\mathrm{pA}_{2}$ consistent with the interaction of this antagonist with $\alpha_{1 \mathrm{~A}}$-adrenoceptors.

Previous studies have shown that the expression of $\alpha_{1}$-adrenoceptor subtypes is differentially regulated by gonadal hormones. We have observed that bilateral orchiectomy induces a plasticity similar to that described in the present study (8) and that testosterone replacement treatment of castrated rats prevents its appearance (12). Recently, Homma et al. (9) observed a specific down-regulation of the mRNA for $\alpha_{1 \mathrm{~A}}$-adrenoceptors associated with a reduced potency of phenylephrine in the rat prostate after androgen deprivation by surgical castration. Sexual maturation, and supposedly the accompanying increase in plasma testosterone levels, 
reduces the mRNA for $\alpha_{1 \mathrm{~A}}$-adrenoceptors in the caput epididymis and increases the mRNA for $\alpha_{1 \mathrm{D}}$-adrenoceptors in the cauda epididymis of the rat (10). Estradiol, on the other hand, has been shown to increase selectively the expression of $\alpha_{1 \mathrm{~B}}$-adrenoceptor binding sites and signaling in the hypothalamus and preoptic area of the female rat $(6,7,11)$.

The results presented here indicate that the contractions of the vas deferens from control rats in response to noradrenaline are mediated by $\alpha_{1 \mathrm{~A}}$-adrenoceptors. However, in addition to $\alpha_{1 \mathrm{~A}}$-adrenoceptors, the $\alpha_{1 \mathrm{~B}}$ subtype also participates in the contractions of the vas deferens from cyproterone acetate-treated rats, indicating that this antiandrogen induces some plasticity in the functional $\alpha_{1}$-adrenoceptor subtypes in the rat vas deferens.

\section{Acknowledgments}

The technical assistance of Ms. Ana Maria Seraphim is gratefully acknowledged.

\section{References}

1. Zhong $H$ \& Minneman KP (1999). Alpha1-adrenoceptor subtypes. European Journal of Pharmacology, 375: 261-276.

2. Docherty JR (1998). Subtypes of functional alpha1- and alpha2adrenoceptors. European Journal of Pharmacology, 361: 1-15.

3. Ford AP, Daniels DV, Chang DJ, Gever JR, Jasper JR, Lesnick JD \& Clarke DE (1997). Pharmacological pleiotropism of the human recombinant alpha1A-adrenoceptor: implications for alpha1-adrenoceptor classification. British Journal of Pharmacology, 121: 11271135.

4. Daniels DV, Gever JR, Jasper JR et al. (1999). Human cloned alpha1A-adrenoceptor isoforms display alpha1L-adrenoceptor pharmacology in functional studies. European Journal of Pharmacology, 370: $337-343$

5. Garcia-Sainz JA, Vazquez-Prado J \& del Carmen Medina L (2000). Alpha 1-adrenoceptors: function and phosphorylation. European Journal of Pharmacology, 389: 1-12.

6. Petitti N, Karkanias GB \& Etgen AM (1992). Estradiol selectively regulates alpha 1B-noradrenergic receptors in the hypothalamus and preoptic area. Journal of Neuroscience, 12: 3869-3876.

7. Karkanias GB, Ansonoff MA \& Etgen AM (1996). Estradiol regulation of alpha $1 \mathrm{~b}$-adrenoceptor mRNA in female rat hypothalamuspreoptic area. Journal of Neuroendocrinology, 8: 449-455.

8. Pupo AS (1998). Functional effects of castration on alpha1-adrenoceptors in rat vas deferens. European Journal of Pharmacology, 351: 217-223

9. Homma Y, Hamada K, Nakayama Y, Tsujimoto G \& Kawabe K (2000). Effects of castration on contraction and alpha(1)-adrenoceptor expression in rat prostate. British Journal of Pharmacology, 131: 1454-1460.

10. Queiroz DB, Mendes FR, Porto CS \& Avellar MC (2002). Alpha1adrenoceptor subtypes in rat epididymis and the effects of sexual maturation. Biology of Reproduction, 66: 508-515.

11. Quesada A \& Etgen AM (2002). Functional interactions between estrogen and insulin-like growth factor-I in the regulation of alpha 1B-adrenoceptors and female reproductive function. Journal of Neuroscience, 22: 2401-2408.

12. Campos M, Morais PL \& Pupo AS (2003). Effects of castration and of testosterone replacement on alpha1-adrenoceptor subtypes in the rat vas deferens. European Journal of Pharmacology, 471: 149155.
13. Arunlakshana O \& Schild $\mathrm{HO}$ (1959). Some quantitative uses of drug antagonists. British Journal of Pharmacology, 14: 48-58.

14. Lafayette SSL (1997). Papel modulador da inervação autonômica e do hormônio sexual masculino sobre os canais de cálcio voltagemdependentes e sua importância no processo contrátil em ducto deferente de rato. Doctoral thesis, Escola Paulista de Medicina, Universidade Federal de São Paulo, São Paulo, SP, Brazil.

15. Castillo CJ, Lafayette $S$, Caricati-Neto A, Sette M, Jurkiewicz $\mathrm{NH}_{\text {, }}$ Garcia AG \& Jurkiewicz A (1992). Low dihydropyridine receptor density in vasa deferentia of castrated rats. British Journal of Pharmacology, 105: 257-258.

16. Aboud R, Shafii M \& Docherty JR (1993). Investigation of the subtypes of alpha 1-adrenoceptor mediating contractions of rat aorta, vas deferens and spleen. British Journal of Pharmacology, 109: 80-87

17. Pupo AS, Jurkiewicz NH \& Jurkiewicz A (1997). Functional change of the balance between alpha $1 \mathrm{~A}$ and alpha 1B adrenoceptor populations after transplantation of the vas deferens to the intestine. Annals of the New York Academy of Sciences, 812: 193-195.

18. Burt RP, Chapple CR \& Marshall I (1995). Evidence for a functional alpha 1A- (alpha 1C-) adrenoceptor mediating contraction of the rat epididymal vas deferens and an alpha 1B-adrenoceptor mediating contraction of the rat spleen. British Journal of Pharmacology, 115: 467-475.

19. Pupo AS, Cavenaghi DL, Campos M, Lucena Morais $P$, Jurkiewicz $\mathrm{NH} \&$ Jurkiewicz A (1999). Effects of indoramin in rat vas deferens and aorta: concomitant alpha1-adrenoceptor and neuronal uptake blockade. British Journal of Pharmacology, 127: 1832-1836.

20. Hanft G \& Gross G (1989). Subclassification of alpha 1-adrenoceptor recognition sites by urapidil derivatives and other selective antagonists. British Journal of Pharmacology, 97: 691-700.

21. Salles J \& Badia A (1991). Mechanisms underlying the differential sensitivity to alpha 1-adrenoceptor activation in the bisected rat vas deferens. British Journal of Pharmacology, 102: 439-445.

22. Vivas NM, Giraldo J, Tabernero A, Vila E \& Badia A (1997). Use of the operational model of agonism and $\left.{ }^{3} \mathrm{H}\right]$ prazosin binding to assess altered responsiveness of alpha1-adrenoceptors in the vas deferens of spontaneously hypertensive rat. Naunyn-Schmiedeberg's Archives of Pharmacology, 356: 383-391.

23. Forray C, Bard JA, Wetzel JM et al. (1994). The alpha 1-adrenergic 
receptor that mediates smooth muscle contraction in human prostate has the pharmacological properties of the cloned human alpha 1c subtype. Molecular Pharmacology, 45: 703-708.

24. Laz TM, Forray C, Smith KE, Bard JA, Vaysse PJ, Branchek TA \& Weinshank RL (1994). The rat homologue of the bovine alpha 1cadrenergic receptor shows the pharmacological properties of the classical alpha 1A subtype. Molecular Pharmacology, 46: 414-422.

25. Scofield MA, Liu F, Abel PW \& Jeffries WB (1995). Quantification of steady state expression of mRNA for alpha-1 adrenergic receptor subtypes using reverse transcription and a competitive polymerase chain reaction. Journal of Pharmacology and Experimental Therapeutics, 275: 1035-1042. 